\title{
Perceptual Justification and the Cartesian Theater
}

\begin{abstract}
According to a traditional Cartesian epistemology of perception, perception does not provide one with direct knowledge of the external world. Instead, when you look out to see a red wall, what you learn first is not a fact about the color of the wall-i.e., that it is red-but instead a fact about your own visual experience-i.e., that the wall looks red to you. If you are to justifiably believe that the wall is red, you must be in a position to justifiably infer this conclusion about the external world from known premises about your own visual experience. Recent anti-Cartesian theorists have pushed back against this traditional model, claiming that the epistemic significance of having a perceptual experience is not exhausted by what can be inferred from the fact that you have the experience. After clarifying an underappreciated commitment of Cartesian accounts and some key motivations for resisting it, I argue that any anti-Cartesian account strong enough to take advantage of these motivations must license a way of updating one's beliefs in response to anticipated experiences that seems diachronically irrational. To avoid this implausible result, the anti-Cartesian must choose between licensing an implausible kind of epistemic chauvinism, or else claiming that merely reflecting on one's experiences can defeat the perceptual justification that they otherwise provide. This leaves us with a puzzle: Although there are powerful motivations for rejecting Cartesianism, any view that avails itself of them faces serious problems of its own.
\end{abstract}

\section{Background}

According to a traditional Cartesian epistemology of perception, perception does not provide one with direct knowledge of the external world. Instead, when you look out to see a red wall, what you learn first is not a fact about the color of the wall-i.e., that it is redbut instead a fact about your own visual experience-i.e., that the wall looks red to you. If you are to know or to justifiably believe that the wall is red, then you must be in a position to justifiably infer this conclusion about the external world from known premises about your own visual experience. ${ }^{1}$

The Cartesian account is sometimes accused of treating ordinary perception on the model of a "Cartesian theater," with perceptual experiences playing the role of mere images displayed before an internal spectator. As I will explain, I think there is some truth to the accusation. What is less clear to me is how this seemingly unappealing model of perceptual justification can be avoided. For even though there are powerful motivations for rejecting the Cartesian account, any alternative view strong enough to appeal to these motivations faces serious problems of its own. My aim in what follows is to explain an underappreciated commitment of the Cartesian account, some motivations for resisting the account, and the problem that confronts any view that takes advantage of these motivations.

\footnotetext{
1 The Cartesian view is so called because it is inspired by Descartes' treatment of perceptual skepticism, though it arguably goes beyond anything he said. For classic examples, see, e.g., (Chisholm, 1966) and (Russell, 1912).
} 
The underappreciated commitment of the Cartesian account concerns the following question: Why does what you are justified in believing depend on your perceptual experiences, while what I am justified in believing depends on my perceptual experiences? The Cartesian, I claim, is committed to the following answer: It is because you know what your own experiences are, but you typically do not know what mine are (and vice versa for me). And this answer commits the Cartesian to claiming that, to whatever extent you do happen to know what my perceptual experiences are, my experiences will justify your beliefs in the same way and to the same degree that your own experiences do. After explaining all of this in Sections 2 and 3 below, I will go on in Section 4 to discuss the problem facing accounts of perceptual justification that follow me in rejecting these Cartesian claims.

But first, I want to consider briefly the more familiar landscape of issues surrounding the Cartesian epistemology of perception. We can start by considering the epistemic situation of an agent who really is in a Cartesian theater:

(CARTESIAN THEATER) You find yourself in a windowless room, which is empty aside from a closed-circuit TV. The TV is hooked up to a camera that is located elsewhere, where it faces a wall of an unknown color. When the TV is switched on, it displays an image of a red wall. You have strong reason to believe that the images on the TV are a reliable guide to the color of the wall, and as a matter of fact the images are both accurate and reliably generated.

It should be uncontroversial that you are justified in believing that the wall is red in CARTESIAN THEATER. And in broad outline, it should also uncontroversial why you are justified. Your only access to the color of the wall comes from the images that you see on your TV screen. So you are justified in believing that the wall is red only because you are in a position to justifiably infer that the wall is red from what you know about these images. ${ }^{2}$ This of course does not mean that you must consciously go through such an inference. But it plausibly does mean that you must be in a position justifiably to do so.

Since you must be in a position to justifiably infer the color of the wall from known premises about the images on your TV screen, this lends credibility to some further familiar claims. First, it is plausible that you still would have been justified in believing that the wall is red even if the images on your TV had been inaccurate, and even if the process that generated them had been objectively unreliable. For you would have the same evidence either way. Second, it is plausible that you would not have been justified in believing that the wall is red if you had lacked background evidence supporting the reliability of the images on the TV screen. For it is plausible that one cannot justifiably infer from premises about the images to conclusions about the wall unless one has evidence supporting that the former is a reliable guide to the latter.

To be sure, both of these further claims are controversial. Some reliabilists about inferential justification, for example, would deny them both. I think we should accept both of these claims, as I have argued elsewhere. ${ }^{3}$ But instead of discussing these claims in more detail

\footnotetext{
${ }^{2}$ For simplicity, I ignore the view that by looking at the images, one can see the wall itself. See (Briscoe, MS Sec. 5) for critical discussion of a view like this. Those sympathetic to such a view could substitute an example where you receive non-imagistic information about the color of a wall.

${ }^{3}$ See especially (Barnett, 2014) and (Barnett, 2015).
} 
here, I want to instead examine a prominent way of resisting a traditional Cartesian epistemology of perception that is willing to grant these claims about Cartesian theaters, and that instead denies that ordinary perception puts us in a comparable situation.

Consider a corresponding case of ordinary visual perception:

(Visual Perception) You look at a wall, and see that it is red. You have strong reason to believe that your visual experiences are reliable.

Although some radical skeptics might deny that it is possible to have strong reason to believe that one's visual experiences are reliable, it should be uncontroversial that if VISUAL PERCEPTION is possible, then in it you are justified in believing that the wall is red. What is controversial is how to explain why you is justified.

I take the the Cartesian account to be this. When you look at a red wall, what you learn first is a fact about your own mind; the fact that you are having an experience as of a red wall (henceforth: a reddish experience). ${ }^{4}$ This reddish experience itself does not give you justification to believe that the wall is red, anymore than a red image on a TV screen does. Instead, it is your knowledge that you have this experience which puts you in a position to justifiably infer that the wall is red, just as knowledge of the red image does in CARTESIAN THEATER.

If we accept this Cartesian account of why you are justified (and accept the plausible but controversial further claims about Cartesian theaters above), then this will leave us with two familiar corollaries. The first is:

(PERCEPTUAL INTERNALISM) Genuinely perceiving never gives one stronger (or weaker) justification for one's perceptual beliefs than merely seeming to perceive does.

The idea behind PERCEPTUAL INTERNALISM is that someone who is hallucinating, or who otherwise has the same experiences as a genuine perceiver, is as justified in her perceptual beliefs as the perceiver is. This is plausibly a consequence of the Cartesian account because both the perceiver and the hallucinator will be in the position of having to infer conclusions about the external world from the same body of evidence.

The second corollary is:

(Perceptual InCREDulism) One is never justified in believing what one perceives unless one has independent evidence that one's perceptual experiences are reliable.

This is plausibly a consequence of the Cartesian account because it is natural to think that one would need a corresponding kind of evidence in order to justifiably infer that the wall is red from one's knowledge that there is a red image on a TV screen. If the Cartesian is right that ordinary perception requires one to make inferences from knowledge of one's experiences, then this plausibly will require corresponding independent evidence supporting the reliability of perception. (See Section 3.1 below for more on this controversial matter.)

\footnotetext{
${ }^{4}$ A disjunctivist can read my talk of having a reddish experience as shorthand for a disjunction, such that an agent has a reddish experience if she either sees a red wall or (merely) seems to see a red wall.
} 
Recent anti-Cartesian theorists, however, have pushed back against this traditional account. These anti-Cartesians do not merely deny the psychological claim that we go around introspecting our experiences and drawing inferences from the introspected premises. Instead, they think that the epistemology of perception is anti-Cartesian in a deeper sense. In their view, your knowledge of your experiences is not what justifies perceptual beliefs. Instead, certain perceptual states contribute to your perceptual justification in a way that is not exhausted by whatever inferences you can draw from your knowledge of your experiences.

Very often, these opponents of Cartesianism also seek to reject one or both of Cartesianism's familiar corollaries. Take, for example, dogmatists and phenomenal conservatives. ${ }^{5}$ These anti-Cartesians are motivated in part by a desire to reject PERCEPTUAL INCREDULISM, which they see as leading to an untenable skepticism about perception. Roughly speaking, their idea is that because one's perceptual experiences themselves can provide a distinctive form of immediate justification not acknowledged by the Cartesian account, they can give you stronger justification for your perceptual beliefs that what the Cartesian account predicts. We will consider how this might give anti-Cartesians an antiskeptical advantage over Cartesianism in Section 3.1 below.

Other anti-Cartesians, such as epistemological disjunctivists, go even further in their rejection of the traditional Cartesian account, and deny that the perceptual states most directly involved in perceptual justification are experiences. ${ }^{6}$ They claim instead that the relevant perceptual states are factive states like seeing. Because these factive states are absent in cases of hallucination, these anti-Cartesians reject not only PERCEPTUAL INCREDULISM but PERCEPTUAL INTERNALISM as well.

Although externalist versions of anti-Cartesianism like disjunctivism are important, our discussion will focus more directly on internalist versions. This is because the contrast with Cartesianism of greatest concern to us arises even without rejecting the Cartesian view that the perceptual states most directly involved in perceptual justification are (non-factive) experiences. Even so, much of what I will say should extend to externalist anti-Cartesian views as well. And I will highlight a few places where the differences between internalist and externalist forms of anti-Cartesianism are important.

It is important that even though both of these familiar forms of anti-Cartesianism reject PERCEPTUAL INCREDULISM, that is not something that I build into the view. Instead, antiCartesianism as I define it is a view about the explanation of perceptual justification. It says that perceptual states themselves can justify beliefs, and that their involvement in the justification of one's beliefs need not always consist in their serving as evidence from which the beliefs are inferred. As we go on, I will have more to say about the additional commitments I think the anti-Cartesian ought to take on, including PERCEPTUAL INCREDULISM. But for now, I define anti-Cartesianism in a minimal way, so that I must work to explain why it should take the more specific form I favor.

\footnotetext{
5 See, e.g., (Brogaard, 2013), (Brown, 2013), (Cohen, 2010), (Cullison, 2010), (Huemer, 2006 and 2007), (Jehle and Weatherson, 2012), (Kung, 2010), (Lycan, 2013), (Moretti, 2015), (Pollock and Cruz, 1999), (Pryor, 2000 and 2013), (Silins, 2008), (Tucker, 2010 and 2013), (Weatherson, 2007), and (Wedgwood, 2013), among many others. Note that while anti-Cartesianism is often coupled with a Moorean reply to the skeptic, this is not something I build in to the view.

${ }^{6}$ See, e.g., (McDowell, 1982 and 1995) and (Pritchard, 2012), and see (Soteriou, 2014) for a helpful review.
} 


\section{Anti-Cartesianism and Perceptual Partiality}

It is time to consider an underappreciated point of contrast between Cartesianism and antiCartesianism. The contrast concerns how each view explains the distinctive epistemic significance of one's own experiences. Both views can accept the datum that the justification of one's beliefs depends more directly on one's own experiences than it does on another person's. But they explain this datum in different ways. The Cartesian's explanation, I will claim, commits the Cartesian to what I call PERCEPTUAL IMPARTIALITY. And as I go on to explain in Section 3.1, the Cartesian's commitment to the more familiar PERCEPTUAL INCREDULISM is a byproduct of this prior commitment.

We can start by again comparing a pair of examples, one involving a Cartesian theater, and the other involving ordinary perception. Here is the first:

(TwO Spectators) You are in a windowless room, which is empty aside from a closed-circuit TV. The TV is is hooked up to a camera that is located elsewhere, where it faces a wall of an unknown color. Another camera also faces the same wall. This camera is connected to a different closed-circuit $\mathrm{TV}$, which sits in a different windowless room, which is occupied by a different person, who we will call 'Other'. Your evidence concerning the reliability of your own and Other's TVs are on a par, in the sense that for any evidence you have concerning your own, you have corresponding evidence concerning Other's. At the moment, both TVs are turned off. But pretty soon, exactly one of the TVs will be turned on. You know all of this.

Consider some claims about this example that should be uncontroversial. The first is that there is an asymmetry between the epistemic significance for you of images on your TV screen and of images on Other's. In particular, if your TV screen is the one that is turned on, and if it displays an image of a red wall, then this can result in your having some justification to believe that the wall is red. How much justification it gives you will depend on your background evidence concerning factors like the reliability of the images on your TV. But regardless of how these details of the example are filled in, the important point is that the images on your TV screen have the potential to affect your justification to believe that the wall is red. If instead Other's TV is turned on, and Other's TV displays an image of a red wall, then this will not result in your having any reason to believe that the wall is red. In short, the images on your TV screen can affect your justification for believing the wall is red in a way that the images on Other's TV do not. And this is true even though your evidence concerning the reliability of Other's TV is on a par with your evidence concerning your own. A second uncontroversial claim concerns the explanation of this asymmetry. The explanation is simply that you are in a position to know what images are displayed on your TV screen-you can see them! - but you are in no position to know what is displayed on Other's TV screen. Because you could know what you images are on your TV, you could be in a position to infer conclusions about the color of the wall from them. But you are in no position to infer conclusions from the images on Other's TV, for the simple reason that you would not know what they are. Thus the asymmetry in the epistemic significance of the images is explained by an asymmetry in access; the images on your TV screen affect what you are justified in believing simply because you are in a position to know what they are.

This explanation has some important consequences for a situation in which you are able to learn about the images on Other's TV screen in some way other than by seeing-for example, where Other is able to tell you what he sees on his TV screen. The consequence is 
that if this other way of knowing about Other's images confers knowledge with the same degree of epistemic security that one gets by seeing, then it would give you just as much justification to believe that the wall is red as you get from seeing the same images on your own TV screen. And moreover, even if your alternative way of accessing Other's TV screen confers less secure knowledge than seeing does, it will give you less justification to believe the wall is red only to the extent that your knowledge of the images on his TV screen is less secure. (We will discuss this further in Section 4.1.)

These consequences follow because by stipulation you have no evidence supporting the reliability of your TV over Other's. If you nevertheless received stronger justification from seeing your own TV's images, this would mean that you could be justified in placing greater confidence in them than in Other's (e.g., by believing what you see on your TV while holding back from believing what you know is displayed on Other's). But that would amount to a kind of irrational chauvinism. For you would be counting the images on your TV as stronger evidence of the truth, simply because that TV is yours.

Plausibly, everyone should accept these claims about Cartesian theaters. But turn now to the second example involving ordinary perception, over which Cartesian and anti-Cartesian views conflict:

(Two PerCeIVERS) You and Other are facing a wall of an unknown color. Your evidence concerning the reliability of your own and Other's visual faculties are on a par, in the sense that for any evidence you have concerning your own, you have corresponding evidence concerning Other's. You are both wearing blindfolds, but pretty soon, exactly one of you will have his or her blindfold removed. You know all of this.

It should be uncontroversial that if you go on to have your blindfold removed, and if you have a reddish experience, then this can give you some reason to believe that the wall is red. Whether it gives you sufficient reason to justify belief that the wall is red will depend on your background evidence about factors like the reliability of your vision. But the important point for now is simply that your experiences can have a positive epistemic impact on your justification to believe that the wall is red. If instead it is Other's blindfold that is removed, and if Other is the one who has the reddish experience, then this will not give you any reason to believe that the wall is red. And this remains true even though your evidence concerning Other's visual reliability is entirely on a par with evidence about your own. Thus it should be uncontroversial that your own experience can asymmetrically affect what you are justified in believing in this way. What Cartesians and anti-Cartesians disagree about is the explanation of this asymmetry.

The Cartesian about perception must explain this asymmetry in the same way that we explain the corresponding asymmetry in TWO SPECTATORS. That is, the Cartesian must say that your perceptual experiences asymmetrically affect your justification simply because you have a special kind of access to facts about your experiences. In TWO SPECTATORS, you know about the images on your TV screen because you can see them, while in TwO PERCEIVERS, you know about your own experiences not by seeing but instead in a special introspective way. But despite this difference, the Cartesian thinks that these cases have in common that the asymmetry in epistemic significance is explained by an asymmetry in access. This is because the Cartesian thinks that the contribution made to one's perceptual justification by perceptual experience is exhausted by one's knowledge of those experiences. 
Notice some apparent consequences of the Cartesian explanation. Since the Cartesian explains the epistemic asymmetry by an asymmetry in access, the Cartesian is committed to granting that if you somehow could have equally secure access to what Other's visual experiences are, this would give you the same degree of justification to believe that the wall is red as you get from your own experiences. And even if it is not possible for you to have equally secure access to Other's experiences as you have to your own, it remains true that you get less justification from knowledge of Other's experiences only to the extent that your access to those experiences is less secure.

These consequences follow from the Cartesian explanation because by stipulation you have no evidence supporting the reliability of your experiences over Other's. For this reason, it would seem irrationally chauvinistic to count your own experiences as stronger evidence of the truth, by placing greater confidence in any conclusions you might infer from what you know about them. The Cartesian thus must accept these consequences, on pain of licensing irrational chauvinism as justified. ${ }^{7}$

In Section 1 above, we noted two familiar corollaries of Cartesianism, PERCEPTUAL INCREDULISM and PERCEPTUAL INCREDULISM. We are now ready to introduce a less familiar, though in my view no less important, third corollary:

(PERCEPTUAL IMPARTIALITY) Having a perceptual experience can never give you substantially stronger justification for a perceptual belief than you would get from knowing that another person has had such an experience.

Note that PERCEPTUAL IMPARTIALITY says that you cannot receive substantially stronger justification from your own experiences than you would get from knowledge of another person's. For a Cartesian can plausibly claim that your own experiences give you slightly stronger justification, for the simple reason that that you plausibly never can be quite as certain of another person's experiences as you are of your own. What the Cartesian seems unable to accept is that even to the extent that you can know another person's experiences, this knowledge still does not confer the same degree of justification as you get from your own experiences. For again, it would seem irrationally chauvinistic to count one's own experiences as stronger evidence of the truth than another person's experiences, unless you have some evidence suggesting that your experiences really do amount to more reliable evidence.

Turn now to the anti-Cartesian, who claims that your merely having a reddish experience can give you justification to believe that the wall is red, in a way that is not fully accounted for by your knowledge of those experiences. Now the anti-Cartesian does not deny that you do have a special way of knowing your own experiences. It is obvious that you do! What the anti-Cartesian denies is that this asymmetry in knowledge fully explains why your own experiences have an epistemic significance for you that Other's do not have. Nor does the anti-Cartesian need to deny that your knowledge of your own reddish experience can give you even more justification to believe that the wall is red, in addition to what you get just by having the experience-although some anti-Cartesians might wish to deny this. ${ }^{8}$ What the anti-Cartesian says is simply that having a reddish experience gives you some justification all on its own.

\footnotetext{
${ }^{7}$ But see Section 4.2 below for one way the Cartesian might try to deflect this charge of chauvinism.

${ }^{8}$ See, e.g., (Lasonen-Aarnio, 2015) for a corresponding issue concerning belief.
} 
The Cartesian and anti-Cartesian thus disagree in the first instance about why your perceptual beliefs are justified, in cases where they are justified. But in disagreeing with the Cartesian's account of why perceptual beliefs are justified, the anti-Cartesian opens the door for sometimes disagreeing with the Cartesian about whether your perceptual beliefs are justified in particular cases. In particular, it allows the anti-Cartesian to hold that there are cases where having a reddish experience can give you substantially stronger justification for a perceptual belief than you would get from merely knowing that Other has had such an experience. In other words, it allows the anti-Cartesian to deny PERCEPTUAL IMPARTIALITY, and accept the contradictory claim that:

(Perceptual Partiality) Having a perceptual experience can sometimes give you substantially stronger justification for a perceptual belief than you would get from knowing that another person has had such an experience.

We have already seen that the Cartesian must deny a thesis like this, on pain of licensing an irrational form of chauvinism as justified. But perhaps it might seem that any view accepting PERCEPTUAL PARTIALITY, including an anti-Cartesian one, must be guilty of the same kind of chauvinism. If I believe what I seem to see, but am less willing to believe what I know that you seem to see, aren't I in an important sense counting my own experience as stronger evidence than yours? I think this is not so obvious.

Consider first what an externalist anti-Cartesian (like a disjunctivist) might say to deflect the charge of chauvinism. She might say that what you are justified in believing depends on the available evidence, which includes all of the facts that you know. When you know that some other person has a reddish experience, then the fact that he has this experience is included in your available evidence. And perhaps when you yourself see a red wall, you might also know that you have a reddish experience, and hence have this fact included in your available evidence. It indeed would be irrationally chauvinistic to count this bit of the available evidence as stronger evidence of the truth than the fact that another person has a similar experience. But that kind of chauvinism need not be involved in believing what you see. For when you see that the wall is red, the fact that the wall is red also is included in your available evidence. And there is nothing chauvinistic about taking this fact to better support that the wall is red than any facts about an agent's experiences do.

I think the internalist anti-Cartesian has a similar way of deflecting the charge of chauvinism. For she might say that what you are justified in believing depends upon the apparent evidence, which includes not only the facts that you know, but also the other things that appear to be facts from your point of view. When you know that another person seems to see a red wall, this fact about his experience is included in your apparent evidence. But when you yourself seem to see a red wall, your apparent evidence includes the apparent fact that the wall is red. Again, there is nothing chauvinistic about counting this apparent fact as stronger evidence that the wall is red than apparent facts that merely concern a given person's experiences. ${ }^{9}$

Of course, it might still be worried that these sorts of moves do not really avoid commitment to an implausible chauvinism, at least for reflective perceivers like us. For we are in a position to reflect on our own experiences, and recognize that they are as capable of error as anyone else's. And even if we do not infer conclusions about the world from

\footnotetext{
${ }^{9}$ For related thoughts on the epistemology of intuitions, see (Wedgwood 2007, Chs. 10 and 11).
} 
premises about those experiences, as the Cartesian alleges, there presumably is some further sense in which we only hold the perceptual beliefs we do as a result of our experiences. Since we are in a position to appreciate all of this on reflection, the worry goes, we are still guilty of irrational chauvinism if we nevertheless place more confidence in our ordinary perceptual beliefs than we would in the conclusions we might infer from another person's experiences.

I have a great deal of sympathy for this worry. Indeed, in Section 4 I will press a problem for anti-Cartesianism that I see as closely related to it. All I claim here is that it is not just obvious that an anti-Cartesian that accepts PERCEPTUAL PARTIALITY must license the kind of flagrant chauvinism that a Cartesian view would need to. Perhaps in the end the antiCartesian who accepts PERCEPTUAL PARTIALITY is committed to licensing irrational chauvinism. But it takes work to show it.

\section{Motivations for Anti-Cartesianism}

We have just seen that the Cartesian cannot plausibly accept PERCEPTUAL PARTIALITY, but that it might be open to the anti-Cartesian to do so. In Section 4 below, I will press a problem for anti-Cartesianism that stems from PERCEPTUAL PARTIALITY. But before doing so, I need to say more to strengthen the association between anti-Cartesianism and Perceptual Partiality. For even though Perceptual Partiality seems open to the anti-Cartesian, this does not mean that the anti-Cartesian must accept PERCEPTUAL PARTIALITY. For one thing, anti-Cartesianism as I have defined it is compatible with the unusual view that having perceptual experiences always gives you weaker justification than you would get from merely knowing about another person's perceptual experiences. More importantly, an anti-Cartesian might hold that while having a perceptual experience gives you a different kind of justification than you would get from merely knowing of another's experiences, you always get the same overall strength of justification from both sources.

To strengthen the connection between anti-Cartesianism and PERCEPTUAL PARTIALITY, we will consider two core motivations for rejecting Cartesianism. These motivations, if they succeed at all, succeed in motivating a form of anti-Cartesianism that accepts PERCEPTUAL PARTIALITY. The upshot is that an anti-Cartesian who appeals to these motivations must accept PERCEPTUAL PARTIALITY.

\subsection{First Motivation: Anti-Skeptical Advantages}

Recall Perceptual InCRedulism, the claim that one cannot be justified in believing what one perceives without independent evidence that one's perceptual experiences are reliable. One familiar motivation for anti-Cartesianism holds that the Cartesian is committed to PerCePtuAl INCREDUlism, and that this in turn leads to skepticism. For this reason, the motivation goes, anti-Cartesianism enjoys an anti-skeptical advantage over Cartesianism. Here I will briefly survey why anti-Cartesianism might enjoy this advantage. In doing so, my purpose is not to develop a novel motivation for anti-Cartesianism, or to settle whether it ultimately succeeds. Instead, I aim merely to highlight that this familiar motivation, if it succeeds at all, succeeds at motivating a form of anti-Cartesian that embraces PERCEPTUAL PARTIALITY.

First consider why it is difficult to avoid perceptual skepticism without rejecting PERCEPTUAL INCREDULiSM. If one's ordinary perceptual beliefs are to be justified, then under PERCEPTUAL INCREDULISM one must have independent evidence supporting that 
one's perceptual experiences are reliable. The relevant notion of 'independence' here can be slippery. But the idea is that one's evidence supporting the reliability of perception cannot itself derive from perception, on pain of vicious circularity. ${ }^{10}$ This raises a problem, because it is hard to see how we might have perception-independent evidence concerning the deeply contingent matter of whether our perceptual experiences are reliable. And for this reason, it is natural to think that our ordinary perceptual beliefs can be justified only if PERCEPTUAL INCREDULISM is false.

This sketch of why PERCEPTUAL INCREDUlism might lead to skepticism is open to question. But it at least has strong prima facie plausibility. The anti-skeptical motivation for anti-Cartesianism assumes that it is correct, and goes on to allege that the Cartesian is committed to PERCEPTUAL INCREDULISM.

To see why the Cartesian, who treats perceptual justification on the model of a Cartesian theater, is arguably committed to PERCEPTUAL INCREDULISM, consider again a simple case in which you find yourself in a Cartesian theater, observing a red image on your TV screen. As we noted in Section 1 above, it is very appealing to accept the following thesis about such a case:

(TV IMAGE INCREDULISM) One cannot be justified in inferring conclusions about the world from premises about TV images unless one has independent evidence that the TV images are reliable.

The problem for Cartesians is that they treat ordinary perception on the model of a Cartesian theater. So if they accept the appealing thesis of TV IMAGE INCREDULISM, they have trouble rejecting PERCEPTUAL INCREDULISM. For if inferring from premises about TV images to conclusions about the external world requires independent evidence that the TV images are reliable, then plausibly the same should go for corresponding inferences from premises about one's perceptual experiences. ${ }^{11}$ Otherwise, one could count one's experiences as stronger evidence than a TV's images, even when one lacks evidence supporting that the experiences are more reliable than the images. And this seems to amount to an irrational kind of chauvinism.

The Cartesian might resist this apparent commitment to PERCEPTUAL INCREDULISM by denying TV IMAGE INCREDULISM. For example, a reliabilist might say that one can be justified in inferring from premises about the TV images to conclusions about the world so long as the images are objectively reliable, and so long as one has no defeaters. A reliabilist view like this could still qualify as 'Cartesian' in my sense, and yet face no obvious skeptical problems. Traditional Cartesians, however, reject reliabilism and other views that might deny TV IMAGE INCREDULISM, as I argue elsewhere we all should. ${ }^{12}$ The anti-skeptical advantage claimed by anti-Cartesians is an advantage over these traditional Cartesians.

The only other way to resist PERCEPTUAL INCREDULISM is by distinguishing in some way between ordinary perception and a Cartesian theater, in order to accept incredulism about

\footnotetext{
${ }^{10}$ See, e.g., (Barnett, 2014) for further discussion.

11 Cf. (Foley, 2001 and 2005) and (Zagzebski, 2012 Chs. 2 and 3), which I read as saying that one has nonevidential reasons to trust the beliefs and experiences of other people.

${ }^{12}$ See especially (Barnett, 2014).
} 
the the latter but not the former. And this is where the Cartesian faces problems that the anti-Cartesian does not. For the Cartesian account holds that perception puts one in the position of having to infer conclusions about the world from known premises about one's experiences, just as in a Cartesian theater one might infer conclusions about the world from known premises about the images on a TV. If that is accepted, then it is hard to see how further differences between the cases could be of assistance. We already have seen that the Cartesian has a difficult time accepting PERCEPTUAL PARTIALITY without licensing obvious chauvinism. And this means that if she rejects PERCEPTUAL INCREDULISM, then she is committed to rejecting a corresponding claim concerning a case where one must infer conclusions about the world from premises about another person's experiences. That is, she is committed to rejecting:

(OTHER PEOPLE'S EXPERIENCES INCREDUlism) One cannot be justified in inferring conclusions about the world from premises about another person's experiences unless one has independent evidence that those experiences are reliable.

The Cartesian would thus need to reject OTHER PEOPLE'S EXPERIENCES INCREDUlism while accepting TV IMAGE INCREDULISM. But this would seem to simply commit her to a different kind of objectionable chauvinism. For if one has no evidence suggesting that an agent's experiences are more reliable than a TV's images, it would seem illegitimately chauvinistic to nevertheless count the experiences as stronger evidence than the images.

The Cartesian thus faces a prima facie skeptical problem. It is plausible that we must reject PERCEPTUAL INCREDULISM if we are to avoid skepticism. But the Cartesian has difficulty doing so. For it is plausible that a spectator in a Cartesian theater cannot justifiably infer conclusions about the world unless he has independent evidence that the images on his TV are reliable. And since the Cartesian treats ordinary perception on the model of a Cartesian theater, she has difficulty accepting this incredulist claim about Cartesian theaters without also accepting a corresponding incredulism about perception.

This is where the anti-Cartesian can plausibly claim an anti-skeptical advantage over the Cartesian. For the anti-Cartesian more plausibly can distinguish between ordinary perception and a Cartesian theater, accepting an incredulist view about the latter but not the former. This is because the anti-Cartesian denies that ordinary perception requires us to make inferences from premises about our own perceptual experiences. For this reason, the anti-Cartesian plausibly can avoid commitment to PERCEPTUAL INCREDULISM, even while granting that independent evidence for the reliability of the TV images would be required by a spectator in a Cartesian theater. Indeed, the anti-Cartesian can grant that we would need independent evidence for the reliability of perception if we were in the position of having to infer our ordinary perceptual beliefs from premises about them. For again, the antiCartesian denies that ordinary perception puts us in the position of having to make such inferences.

This anti-skeptical motivation for anti-Cartesianism is by no means beyond question. Perhaps the Cartesian could find a way to avoid PERCEPTUAL INCREDULISM after all, or else of accepting it without falling into skepticism. Alternatively, perhaps it could be claimed that the anti-Cartesian cannot ultimately succeed in resisting skepticism, either. I do not hope to settle these matters here. Instead, I want to emphasize only that if the anti-Cartesian does enjoy this anti-skeptical advantage over the Cartesian, this is only because the anti-Cartesian is better positioned to accept Perceptual Partiality. For the anti-Cartesian is in no 
better position than the Cartesian to distinguish between inferences from premises about TV images and inferences from premises about an agent's experiences. And so the antiCartesian is in no better position to accept TV IMAGE INCREDULISM and reject OTHER PEOPLE'S EXPERIENCES INCREDULISM. Rather, the anti-Cartesian's advantage comes in distinguishing ordinary perception from a case where one infers conclusions about the world from premises about an agent's experiences. This arguably could enable the anti-Cartesian, unlike the Cartesian, to accept OTHER PEOPLE'S EXPERIENCES INCREDULISM while rejecting PERCEPTUAL InCREDUlism. In doing so, the anti-Cartesian must hold that one sometimes can be justified in one's perceptual beliefs even though one would not be justified in inferring conclusions about the world from premises about another agent's experiences. And this means accepting PERCEPTUAL PARTIALITY.

\subsection{Second Motivation: We Can't be Cartesians “All the Way Down”.}

The second motivation for anti-Cartesianism appeals to the following observation: We cannot be Cartesians "all the way down". Specifically, we cannot plausibly extend Cartesianism from perceptual experience to other states like belief and knowledge. ${ }^{13}$ For it is not plausible that the justification of your beliefs depends on your own beliefs and knowledge only in the way that it can depend on another person's. After explaining why, I will discuss how this might support anti-Cartesianism about perception.

Consider first Cartesianism about knowledge itself. ${ }^{14}$ The Cartesian about knowledge takes what the perceptual Cartesian said about perceptual experiences, and extends it to knowledge. The perceptual Cartesian denied that perceptual experiences themselves can directly affect what one is justified in believing. Whenever experiences are involved in the justification of a belief, it is only indirectly, in virtue of one's knowledge of the experiences giving one inferential justification for the belief. If we try to extend these claims to knowledge itself, however, it leads to a contradiction.

It is clear that knowledge can at least be indirectly involved in the justification of one's beliefs. For example, suppose you have background knowledge that a picnic will be cancelled if it rains, and you gain new knowledge that it will rain. Surely this can at least result indirectly in your being justified in believing that the picnic will be cancelled. Yet by stipulation, the Cartesian about knowledge would deny that your knowledge that it will rain is what gives you justification to believe that the picnic will be cancelled. Instead, she says that what gives you justification must be your higher-order knowledge that you know this. But at the same time, the Cartesian about knowledge also denies that your higher-order knowledge can give you justification to believe the picnic will be cancelled, for the same reason. Thus Cartesianism about knowledge itself is inconsistent.

This quick refutation applies only to a general Cartesianism about knowledge, which by stipulation denies that any knowledge, even higher-order knowledge, can directly give one justification for beliefs. It leaves open more restricted Cartesian views about belief and

\footnotetext{
13 See also (Brown, 2013) and (Wedgwood, 2007, Chs. 10 and 11) for anti-Cartesianism about intuitions, and Pollock and Cruz (1999) for anti-Cartesianism about memory experiences. And see (Robson, 2012) for a review of loosely related issues concerning aesthetic experience, including Wollheim's (1980, p.233) Acquaintance Principle.

14 The view is so called with apologies to Descartes, who I interpret as anti-Cartesian about clear and distinct perceptions that he took to be necessary and sufficient for knowledge (Barnett, MS).
} 
knowledge. But the quick refutation is enough to show that we cannot be Cartesians "all the way down". For some mental or epistemic states, just being in those states affects what one is justified in believing. Their epistemic significance is not always exhausted by the inferential justification provided by knowledge that one is in them. Even a Cartesian about other states must admit that some states of higher-order knowledge are states of this kind. So the issue is not whether mental states can affect one's justification in this way, but instead simply which ones do.

Now there are a number of possible views that are anti-Cartesian about higher-order knowledge, but that adopt Cartesianism about other states of knowledge and belief. While I think all these views face similar problems, I will focus on a particular view that is inspired by recent debates over peer disagreement and higher-order evidence. The view, which I call 'Cartesianism about belief' holds that neither first-order beliefs nor first-order knowledge directly give one justification for further beliefs. Instead, when you have a belief that is supported by your first-order evidence, this can affect what justification you have for further beliefs only in virtue of what you can justifiably infer from your knowledge that you have the belief. $^{15}$

Like Cartesianism about perception, Cartesianism about belief is a view about why particular mental states affect your justification for further beliefs. But unlike Cartesianism about perception, any explanation it could offer faces an immediate problem. For consider what it says about a simple case where you know that a picnic will be cancelled if it rains, and then come justifiably to believe that it will rain. Surely this too can at least result indirectly in your having justification to believe that the picnic will be cancelled. But the Cartesian denies that justifiably believing that it will rain can be what directly gives you justification to believe that the picnic is cancelled. Instead, it is your knowledge that you believe it will rain that must give you inferential justification supporting that the picnic will be cancelled. But why would the fact that an agent believes it will rain inferentially support that a picnic will be cancelled? The obvious answer is that it does so by supporting that it will rain. But you already justifiably believe that it will rain, and the Cartesian denied that this can be what gives you justification to believe that the picnic will be cancelled! The Cartesian about belief thus has no apparent way of explaining how knowledge of your belief that it will rain could give you inferential justification to believe that the picnic will be cancelled.

Also like Cartesianism about perception, Cartesianism about belief lends itself to further views about whether you are justified in particular cases. In particular, I think the Cartesian must accept a principle similar to PERCEPTUAL IMPARTIALITY. In this respect, Cartesianism about belief and perception are closely aligned. So I will set aside the preceding objection, and focus on others with more immediate relevance to Cartesianism about perception.

Consider an example:

\footnotetext{
${ }^{15}$ Notice that on this Cartesian view, the higher-order knowledge that does the justifying is knowledge that you have the belief, and not knowledge whether you hold the belief justifiably, or whether it is supported by your first-order evidence. I think this makes the view a better counterpart to traditional Cartesian views of perception, on which it is crucial that one's evidence about one's own perceptual states be limited to what can be known directly by introspection. I take it that plausibly can achieve higher-order knowledge of a belief directly via introspection, but not knowledge of whether it is justified. But in any case, some of my objections will apply to Cartesian views that incorporate these other kinds of higher-order knowledge.
} 
(TwO Believers) You and Other both know that the picnic will be cancelled if it rains. Right now, you both suspend judgment on whether it will rain. But pretty soon, one of you will learn first-order meteorological evidence that will lead you to settle on a belief. You have strong but misleading higher-order evidence that you are highly unreliable at evaluating meteorological evidence, and you have equivalent higher-order evidence concerning Other. (For example, you might have misleading evidence supporting that you are both impaired by drowsiness, hypoxia, or a drug.) As a matter of fact, whoever comes to hold a belief will believe that it will rain. And despite this misleading higher-order evidence, you are in fact highly reliable, and the meteorological evidence supports this belief.

First consider what we should say if Other is the one who goes on to believe that it will rain. It should be uncontroversial that even if you know that Other holds this belief, this knowledge will have little effect on your justification to believe that the picnic will be cancelled. For unlike the more schematic TwO SPECTATORS and TwO PERCEIVERS, in TwO BELIEVERS it is stipulated that your higher-order evidence is unfavorable. So even if Other himself has strong meteorological evidence supporting his belief that it will rain, your evidence, including what you know about Other, will not support that it will rain. And for this reason, you cannot plausibly be justified in believing either that it will rain or that the picnic will be cancelled.

Now consider what the Cartesian must say if you are the one who believes that it will rain. The Cartesian says that just as with Other, this puts you in the position of having to infer whether the picnic will be cancelled from the evidence that you believe it will rain. We have said that you would not be justified in doing so when your evidence is instead that Other holds this belief. So it would seem irrationally chauvinistic for you to do so when you are the one who holds it. For this would mean treating your own belief as stronger evidence of the truth, even though your evidence about your own reliability and Other's is equivalent.

In short, the Cartesian about belief must accept an impartiality principle similar to PERCEPTUAL IMPARTIALITY. For reasons that will emerge shortly, it is worth considering a principle that, while no less plausibly a commitment of Cartesianism, is stronger than what we considered for perception:

(STRONG DOXASTIC IMPARTIALITY) Holding a belief can never have substantially stronger effects on your justification for other beliefs than would result from knowing that another person holds that belief.

The Cartesian should accept STRONG DOXASTIC IMPARTIALITY because she says that regardless of who holds a belief, its epistemic significance is exhausted by what can be inferred from the fact that the person holds is. So if the Cartesian allowed holding the belief yourself to have some further epistemic effect that knowing of Other's belief does not have, then this would amount to licensing irrational chauvinism.

The Cartesian therefore must claim that, if you are the one who believes that it will rain, your holding this belief will have little effect on your justification to believe that the picnic will be cancelled. She must claim this because that is what we all should say when it is Other who holds this belief. But this claim has potentially objectionable consequences. 
The first is this: The Cartesian must say that your belief that it will rain itself is unjustified, despite its being supported by your meteorological evidence. For consider the plausible principle that for arbitrary $\mathrm{p}$ and $\mathrm{q}$,

(Modus Ponens Closure) If you justifiably believe that $\mathrm{p}$ and know that if $\mathrm{p}$ then $\mathrm{q}$, then you have justification to believe that $\mathrm{q}$.

If you justifiably believed that it will rain, then by MODUs PONENS Closure you would have justification to believe that the picnic will be cancelled. But you would not have justification to believe that the picnic will be cancelled merely from knowing that Other believes it will rain. So by accepting STRONG DOXASTIC IMPARTIALITY, the Cartesian is committed to saying that your belief that it will rain is unjustified.

Indeed, Cartesianism about belief seems committed to calibrationism, a view with recent prominence in discussions of peer disagreement and higher-evidence. ${ }^{16}$ Although calibrationist views can vary, the rough idea is that once you arrive at an initial first-order belief in response to your first-order evidence, the all-things-considered justified doxastic attitude is the one best supported by your higher-order evidence about yourself, including the fact that you initially arrived at whatever belief you did. To see why the Cartesian must accept this strong form of calibrationism, suppose to the contrary that having strong firstorder evidence that it will rain could give you stronger justification to believe that it will rain than you would get from the higher-order evidence alone. This would mean that it gives you stronger justification than you would get from merely knowing that Other believes that it will rain, since concerning Other this higher-order evidence is your total evidence. And if you can have stronger justification to believe that it will rain, then this stronger justification to believe that it will rain should also result in stronger justification to believe that the picnic will be cancelled. Thus we must accept calibrationism, or else accept the following:

(DOXASTIC PARTIALITY) Holding a belief can sometimes give you substantially stronger justification for other beliefs than you would get from mere knowledge that another person holds that belief. ${ }^{17}$

Yet Doxastic Partiality contradicts Strong DoXAstic ImParTiality, which the Cartesian must accept. The Cartesian thus has stronger calibrationist commitments than many philosophers are willing to accept.

Of course, while calibrationism remains controversial, many accept or at least defend it. But I think even these philosophers should reject a second objectionable commitment of Cartesianism, which goes beyond anything calibrationists endorse. For by STRONG

16 For sympathetic discussions of calibrationism and the closely related equal weight view of peer disagreement, see, e.g., (Elga, 2007), (Christensen, 2010), (Sliwa and Horowitz, 2015) and (Vavova, 2014). For critical discussions, see, e.g., (Kelly, 2010), (Lasonen-Aarnio, 2014), (Schoenfield, 2015), and (Weatherson, MS). Although I have endorsed a calibrationism-like view regarding external sources of information (Barnett, 2014), I was careful not to extend it to one's own beliefs and experiences.

${ }^{17}$ Here I assume that if we reject calibrationism, then it is the justified belief that it will rain which justifies the belief that the picnic will be cancelled. But Alex Worsnip suggests that there might be room for a distinct view holding that it is the meteorological evidence itself which justified the belief that the picnic will be cancelled. Although this view is incompatible with calibrationism and Cartesianism about belief, perhaps it can reject DOXASTIC PARTIALITY. But note that even if so, this view would not allow us to avoid the weaker principle WEAK DOXASTIC PARTIALITY, which I discuss below. 
DOXASTIC IMPARTIALITY, the Cartesian must claim that your belief that it will rain does not in any way affect your justification concerning whether the picnic will be cancelled. So let us grant for the sake of argument the calibrationist claim that your belief that it will rain is unjustified. As we will now see, the Cartesian's claim is objectionable even if so.

Start with the common observation that agent with logically incoherent doxastic attitudes are guilty of irrationality, at least barring exceptional circumstances. ${ }^{18}$ For example, consider an agent who believes that $\mathrm{p}$, and who knows that if $\mathrm{p}$ then $\mathrm{q}$, but who nevertheless believes that not-q. This agent manifests irrationality by holding these inconsistent beliefs. Consider also an agent who believes that $\mathrm{p}$, and who knows that if $\mathrm{p}$ then $\mathrm{q}$, but who nevertheless suspends judgment on whether $\mathrm{q}$. This agent, too, manifests irrationality in suspending judgment on an obvious consequence of other things she believes. ${ }^{19}$

Similarly, if one believes that it will rain in TwO BELIEVERS, then one manifests irrationality by suspending judgment or disbelieving that the picnic will be cancelled. For this reason, I think these doxastic attitudes could not be justified, so long as you believe that it will rain. That is, so long as you believe it will rain, you could not justifiably disbelieve that the picnic will be cancelled. Nor could you justifiably suspend judgment on whether the picnic will be cancelled. To be sure, if calibrationists are right that your belief that it will rain is itself unjustified, then you furthermore could not justifiably believe that the picnic will be cancelled! But that does not mean that other doxastic attitudes would be justified. Instead, it means that you are in a low-grade epistemic tragedy, in which no possible doxastic attitude is justified, so long as you retain your belief that it will rain. (I call it 'low-grade' because you have a way out: giving up your unjustified belief that it will rain.)

In making these claims about the epistemic effects of even unjustified beliefs, I commit myself to a principle like the following:

(NARrow-Scope Modus Ponens) If you believe that $\mathrm{p}$ and know that if $\mathrm{p}$ then $\mathrm{q}$, then you are rationally required to believe that $\mathrm{q}$.

Here I understand the notion of rational requirement in the following semi-stipulative way: You are rationally required to believe that $\mathrm{q}$ iff you cannot justifiably hold any doxastic attitude to $\mathrm{q}$ other than belief. (If there can be at least low-grade epistemic tragedies, being rationally required to hold a belief is not sufficient for having justification for it. Whether rational requirement is necessary for justification is a controversial matter, closely related to whether rationality is permissive. ${ }^{20}$ )

There are two differences between NARROW-SCOPE MODUS PONENS and the more familiar Modus Ponens Closure. First, NARrow-Scope Modus POnens is missing a deontic operator in the antecedent. Satisfying the antecedent requires believing that $\mathrm{p}$, but not justifiably believing that p. Second, the condition specified in the consequent has been

18 See, e.g., (Lasonen-Aarnio, 2008) and (Schechter, 2013) for recent discussion of circumstances where coherence requirements allegedly fail. I think these and other problems critics have raised for coherence requirements are orthogonal to the present discussion.

${ }^{19}$ Here I take suspended judgment to be a positive doxastic attitude. One does not qualify as suspending judgment if one has never settled on an attitude, for example if one has never considered the matter.

${ }^{20}$ See, e.g., (White, 2005) and (Schoenfield, 2014). 
(arguably) weakened. It would be implausible to hold that merely believing that $\mathrm{p}$ (while knowing if $\mathrm{p}$ then $\mathrm{q}$ ) is sufficient for having justification to believe that $\mathrm{q}$. For that would mean that an agent who believes he is Napoleon (and who has some basic historical knowledge) has justification to believe that he was defeated at Waterloo. Instead, NARROWSCOPE MODus PONENS says only that cannot justifiably hold a doxastic attitude to q other than belief. So it means, for example, that one who believes he is Napoleon, and who knows that if so he was defeated at Waterloo, cannot justifiably believe that he was not defeated at Waterloo.

The Cartesian about belief must deny that unjustified beliefs can have these downstream epistemic effects that I have been suggesting. We have already observed that when Other is the one who believes that it will rain, knowing of Other's belief would not give you justification to believe that the picnic will be cancelled. For by stipulation, your evidence supports that Other is unreliable. But similarly, knowing of Other's belief would not prevent you from justifiably holding other doxastic attitudes to whether the picnic will be cancelled, such as suspended judgment.

To be sure, even though these considerations give us reason to reject Cartesianism about belief, they do not get us all the way to DOXASTIC PARTIALITY, which speaks to justification rather than rational requirement. But it does get us to the contradictory of STRONG DOXASTIC IMPARTIALITY, namely:

(WeAK Doxastic Partiality) Holding a belief can sometimes have substantially stronger effects on your justification for other beliefs than would result from knowing that another person holds that belief.

The upshot is that the Cartesian, who is committed to STRONG DOXASTIC IMPARTIALITY, must deny that believing it will rain prevents you from justifiably suspending judgment or disbelieving that the picnic will be cancelled.

Now it might seem that in denying this, the Cartesian is in good company. For the epistemic significance of unjustified belief has been the subject of considerable controversy in recent debates between wide- and narrow-scopers about rational requirements. ${ }^{21}$ The wide-scopers claim that it is a mistake to think of rationality as requiring particular attitudes in the way NARROW-SCOPE MODUS PONENS alleges. These philosophers instead opt for wide-scope requirements like:

(Wide-SCOPE MOdus PONENS) Rationality requires that (if you believe that $\mathrm{p}$ and know that if $\mathrm{p}$ then $\mathrm{q}$, then you believe that $\mathrm{q}$ ).

Now I admit that Wide-SCOPE MODUs PONENS might not have the straightforward implications for justification that NARROW-SCOPE MODUS PONENS does. Justification is an evaluative notion typically applied to particular attitudes, and it is perhaps up for grabs what implications wide-scope requirements should have for the evaluation of particular attitudes. Presumably we should at least say that if a set of attitudes jointly violate a wide-scope requirement, then at least one of them is unjustified. But the Cartesian can allow this. For she holds that your belief that it will rain is unjustified, independently of whether you violate any wide-scope requirements with your attitude to whether the picnic will be cancelled.

\footnotetext{
${ }^{21}$ See, e.g., (Broome, 1999 and 2013), (Kolodny, 2005),(Lord, 2014), and (Worsnip, 2015).
} 
Yet it is at least plausible, even if we opt for wide-scoping, that the violation of a rational requirement can impugn the justification of otherwise justified beliefs. In particular, if you believe that it will rain in TWO BELIEVERS, then plausibly you cannot justifiably believe that the picnic will not be cancelled, even if you otherwise have good reason to believe this. And it is furthermore plausible that you could not justifiably suspend judgment about whether it will be cancelled. These claims have an independent intuitive plausibility, even if we opt for a view about rational requirements that does not straightforwardly entail them.

It is time to take stock. Cartesianism about belief is in bad shape. And if we adopt antiCartesianism about belief, that opens the door for anti-Cartesianism about perceptual experience as well. To be sure, anti-Cartesianism about belief does not straightforwardly entail anti-Cartesianism about perceptual experience. For it could be that beliefs and perceptual experiences simply differ epistemically. Coherentists, for example, often stress what they see as fundamental differences between belief and experience in supporting their claim that the only thing that could justify a belief is another belief. But recent antiCartesians reply by stressing what they see as important similarities. Like belief, these antiCartesians claim, perceptual experiences have representational content. And also like belief, but unlike other states with representational content like desires, perceptual experiences in some sense present their representational content as being true. ${ }^{22}$ For this reason, it is plausible that perceptual experiences, like beliefs, partially determine what one's apparent evidence is. I take this to strengthen attempts to deflect the charge of chauvinism that we considered at the end of Section 2 above.

These are difficult matters, and I will not try to adjudicate them here. Instead, my aim is simply to note that to the extent that we are attracted to anti-Cartesianism about experience because of these apparent similarities between perceptual experiences and beliefs, we will have reason to accept PERCEPTUAL PARTIALITY. This is because our main motivations for rejecting Cartesianism about belief appealed to corresponding partiality principles, DOXASTIC PARTIALITY and WeAK DOXASTIC PARTIALITY. Now it is true that Weak Doxastic Partiality differs from Perceptual Partiality. For WEAK Doxastic PARTIALITY says merely that your beliefs can affect your justification in ways that another person's do not, and not that your beliefs do so specifically by giving you justification for beliefs that another person's does not. But the reason why narrow-scoping supported only this weaker partiality principle for belief is because of the distinction between rational requirement and justification. The distinction is important in the case of belief, because the unjustified belief that it will rain can rationally require you to believe that the picnic will be cancelled even though it does not justify you in doing so. But I think that it is unlikely that the distinction between justifying and rationally requiring a belief will be of similar importance when it comes to experience. Since experiences cannot be unjustified in the first place, it is not clear that an experience could rationally require a perceptual belief without thereby justifying it. ${ }^{23}$ And so an anti-Cartesianism about experience, if modeled on anti-

\footnotetext{
${ }^{22}$ For helpful discussion of these issues, see (Pryor, 2005).

23 Those with worries about the cognitive penetrability of perception-e.g., (Siegel 2012 and 2013)—might think it is possible for perceptual experiences to be epistemically defective in some broader way that makes them unsuitable to justify a perceptual belief even when they require it. But even if so, I think this will not substantially affect the main thread of our discussion. The problem for anti-Cartesianism that I present in Section 4 could arguably be recast in terms of requirements rather than justifications, or even simply be restricted to cases in which it is stipulated that the perceptual states in question are not epistemically defective.
} 
Cartesianism about belief that accepts either DOXASTIC PARTIALITY or WEAK DOXASTIC PARTIALITY, should accept PERCEPTUAL PARTIALITY.

\section{A Problem for Anti-Cartesianism}

Let's consider the big picture. According to the traditional Cartesian epistemology of perception, one's perceptual beliefs are justified if at all by inferences from known premises about one's perceptual experiences. But anti-Cartesians say that perceptual states themselves can provide one with perceptual justification to a degree that cannot be accounted for in this way. This allows anti-Cartesians to accept PERCEPTUAL PARTIALITY without obvious chauvinism, unlike Cartesians. And indeed, the core motivations for anti-Cartesianism also support PERCEPTUAL PARTIALITY, meaning that the anti-Cartesian cannot avail herself of these motivations without also accepting PERCEPTUAL PARTIALITY.

What remains to be seen is whether there is some subtler way in which accepting PERCEPTUAL PARTIALITY ultimately commits the anti-Cartesian to licensing objectionable chauvinism or some other sort of irrationality. And it is here that I think the anti-Cartesian faces a problem. So although in my view the motivations for rejecting Cartesianism are powerful, there also is a powerful objection to any form of anti-Cartesianism that can avail itself of these motivations by accepting PERCEPTUAL PARTIALITY. The Cartesian analogy between ordinary perception and a Cartesian theater, despite its many difficulties, is not easily dispensed with.

The problem for anti-Cartesianism arises from the fact that just as you can know about another person's experiences, you also can know about the experiences that you had in the past, or that you will have in the future. Consider an example:

(ANTICIPATED EXPERIENCE) Shortly before noon, you are wearing a blindfold and facing a wall. You know that at noon, the blindfold will be removed, and that when it is, you will have an experience as of a red wall.

What should the anti-Cartesian say about the epistemic significance of knowing that you will have a reddish experience at noon? Is it epistemically akin to knowing that another person has a reddish experience? Or is it more like actually having the experience now? For a more precise formulation of this question, let's call the justification that the anti-Cartesian says that you get from actually having an experience your proprietary justification. (That is, the proprietary justification is whatever you get in excess of what you would get from knowing that another person had such an experience.) The question at hand is whether knowing about your own future experiences gives you proprietary justification now for perceptual beliefs.

There are strong prima facie motivations for thinking that the anti-Cartesian cannot allow knowledge of one's future experiences to give one proprietary justification now. For it would seem that the only way this knowledge could justify you in believing that the wall is red is by allowing you to justifiably infer that the wall is red from the premise that you will have a reddish experience at noon. And it would be illegitimately chauvinistic to infer that the wall is red from this premise unless you also would be willing to infer the same conclusion from the premise that Other will have a reddish experience at noon. Thus the anti-Cartesian cannot say that knowledge of one's own future experience gives one proprietary justification for believing that the wall is red any more than the Cartesian was able to say this for knowledge of one's own present experiences. 
Now I am not entirely sure that this prima facie motivation should be accepted, as I will explain in Section 4.2 below. But let us for now suppose that it is, and see the problem that this raises for the anti-Cartesian. The anti-Cartesian accepts Perceptual Partiality, and thus says that having a reddish experience now can give you proprietary justification for believing that the wall is red-justification that can be stronger than what you would get from merely knowing that another person has or will have a reddish experience. But merely knowing that you will have a reddish experience yourself in a few minutes does not give you that kind of proprietary justification right now. The anti-Cartesian must therefore claim that even when you know in advance that you will have a reddish experience at noon, when noon arrives and you actually have that reddish experience, this will give you stronger justification than you had to begin with.

The problem for the anti-Cartesian is that this final claim licenses a way of updating one's beliefs and credences that seems to manifest diachronic irrationality. For suppose that before noon you withhold belief that the wall is red, even though you know that at noon the wall will look red to you. It seems irrational for you suddenly to be convinced that the wall is red once your blindfold is removed and you seem to see a red wall. You knew that this would happen! More generally, it seems irrational for you to substantially increase your confidence at noon that the wall is red, merely because you are having the very experience that you knew in advance you would have. But if the anti-Cartesian were right that your degree of justification for believing the wall is red increases substantially at noon, then it would be rational for you to substantially increase your confidence that the wall is red. If it isn't, the anti-Cartesian must be wrong.

The anti-Cartesian has a number of possible responses to this apparent problem. But before considering these options, I want to say briefly why this problem for antiCartesianism is more general and less avoidable than two more familiar objections to particular versions of anti-Cartesianism.

First consider a prominent Bayesian objection to certain versions of dogmatism, which embrace a Moorean reply to skepticism. ${ }^{24}$ These Moorean dogmatists hold that one's experiences can give one justification to believe that one is not in a skeptical scenario, even when one's being in the skeptical scenario would entail that one has those very experiences. For example, where BIV is the proposition that one is a brain in a vat who has a nonveridical reddish experience, and RED is the proposition that one has a reddish experience, the Moorean holds than having a reddish experience can justify one in rejecting BIV even though BIV entails RED. The familiar Bayesian objection to this claim appeals to the theorem of the probability calculus that if BIV entails RED, then $\operatorname{Pr}(\sim \mathrm{BIV} \mid \mathrm{RED}) \leq$ $\operatorname{Pr}(\sim \mathrm{BIV})$. The objection says that since one's prior conditional probability for $\sim$ BIV given RED can be no higher than one's prior unconditional probability for RED, having a reddish experience cannot give you justification to believe that $\sim \mathrm{BIV}$.

This is an important objection to the Moorean reply to skepticism. But the relationship between anti-Cartesianism an the Moorean reply is slippery. Not only might anti-Cartesians

\footnotetext{
${ }^{24}$ See (White, 2006) for a canonical presentation of this objection to Pryor's (2000) dogmatism, as well as other objections.
} 
reject the Moorean reply, ${ }^{25}$ Cartesians might embrace it. ${ }^{26}$ And even if the anti-Cartesian does embrace the Moorean reply, she has available several plausible responses to the Bayesian objection. ${ }^{27}$ Here I will merely highlight my preferred response, which has been discussed in depth by Luca Moratti (2015). The response holds that just because $\operatorname{Pr}(\sim \mathrm{BIV} \mid$ $\mathrm{RED}) \leq \operatorname{Pr}(\sim \mathrm{BIV})$, that does not mean that having a reddish experience cannot confer justification for believing $\sim$ BIV. For it denies that the epistemic significance of having a reddish experience is exhausted by one's conditionalizing on the proposition that one has it. Anti-Cartesians should be prepared to deny this. For conditionalizing on a proposition is a close cousin of making inferences from one's knowledge of that proposition. And the antiCartesian's core idea is that the epistemic significance of having an experience is not exhausted by what can be inferred from the proposition that one has it.

Consider now a second familiar objection. This objection concerns externalist forms of anti-Cartesianism like epistemological disjunctivism. These externalist views claim that the factive state of seeing can give one perceptual knowledge even when merely seeming to see the same thing would fail to even give one justification for a perceptual belief. The prima facie problem for these views is that they have the counterintuitive implication that one who unwittingly hallucinates a red wall is unjustified in believing that the wall before her is red. But externalists have tried to explain away the intuition that such an agent is justified by distinguishing between justification and blamelessness. ${ }^{28}$ Sure enough, they say, such an agent is blameless in believing that the wall is red. But this kind of blamelessness is not sufficient for justification. However, the problem that I raise for anti-Cartesianism instead only requires blamelessness to be necessary for justification. This is because it charges antiCartesianism with licensing as justified a way of updating one's beliefs that is positively blameworthy. So long as blamelessness is necessary for justification, this updating procedure could not yield justified belief, as the anti-Cartesian is apparently committed to claiming. So even though these externalist forms of anti-Cartesianism are not our main focus, I think the problem I raise is more pressing for them than this familiar problem.

It is time now to consider an anti-Cartesian's options for responding to the problem I have just raised. In Section 4.1, I will consider the prospects for biting the bullet, and accepting that one gains justification at noon to believe that the wall is red. In Sections 4.2 and 4.3, I will consider two ways that the anti-Cartesian might try to avoid the commitment to saying this. Finally, in Section 4.4 I will explain why the anti-Cartesian who wishes to hang on to PERCEPTUAL PARTIALITY has no further options remaining.

\subsection{First Option: Biting the Bullet}

Can the anti-Cartesian bite the bullet, and accept that at noon you gain additional justification for believing the wall is red?

\footnotetext{
${ }^{25}$ E.g., (Silins, 2008).

${ }^{26}$ E.g., (Vogel, 2014).

27 E.g., (Cohen, 2010), (Jehle and Weatherson, 2012), (Kung, 2010), (Moretti, 2015), (Pryor, MS and 2013), (Vogel, 2014), and (Weatherson, 2007).

28 See, e.g., (Littlejohn, 2012) and (Pritchard, 2012). And see (Miracchi, forthcoming) for helpful critical discussion, as well as an alternative externalist proposal.
} 
Here is one defense of biting the bullet: Any view about perception must say something unappealing at some point. And what the anti-Cartesian says here, while counterintuitive, is less bad than what alternative views must say elsewhere.

In my view, this is the best defense of biting the bullet. I now consider some other defenses, which attempt to make biting the bullet seem more appealing than I have made it out to be. I think these fail.

The first grants that your degree of justification increases at noon, but denies that this licenses an irrational updating procedure. It says: Simply because your degree of justification increases, that does not mean your degree of confidence ought to increase.

I admit that there might be different ways of understanding talk of degrees of justification, perhaps some of which divorce the notion from rational degrees of confidence. And perhaps on some of these, it could be plausible that your degree of justification increases at noon. For example, perhaps you gain a more direct kind of knowledge at noon that the wall is red, even if you rationally had high confidence already. But I think that the anti-Cartesian is in no position to fall back on a notion of degrees of justification that divorces it from rational degrees of confidence. For this would undermine the strongest motivations for anti-Cartesianism. Consider, for example, the anti-skeptical advantage over the Cartesian. The anti-Cartesian could not claim this advantage if our perceptual experiences merely gave us a kind of proprietary justification that affects the strength of our justification for perceptual beliefs, without also permitting us to place more confidence in them. This kind of proprietary justification would do nothing to help us respond to the skeptical challenge that we are irrational for being as confident as we are that we have hands. If we were worried that our perceptual beliefs, despite being rational and true, were merely deficient in some further way, then perhaps PERCEPTUAL PARTIALITY could still be of assistance. But it is unclear what that further worry would be, and it does not seem to be the core skeptical challenge that anti-Cartesians have traditionally taken their view to help us overcome.

Another defense of biting the bullet holds that even if you know in advance that you will have a reddish experience, you can never be quite certain. But when you actually have a reddish experience at noon, then you can be certain. As a result, you can be more confident that the wall is red.

I admit that this this defense gives a plausible explanation of why your confidence might justifiably increase slightly at noon. Indeed, it is one even Cartesians could accept. For plausibly, even when one knows some evidence e that inferentially supports $p$, this is compatible with one having some room for doubt about e and thus about $\mathrm{p}$ as well. And so it is plausible that increasing one's degree of certainty in e beyond a minimum threshold required for knowledge might increase one's degree of confidence in $\mathrm{p}$ at least slightly.

Even so, I think this defense cannot plausibly explain why one's degree of confidence for $\mathrm{p}$ could rationally increase more than slightly. If one knows that $\mathrm{e}$, then one has at most a little room for doubt about e. So there will be little room for one's degree of certainty in e to increase, and thus little room for one's confidence in $\mathrm{p}$ to increase as a result of an increase 
in the certainty of $e^{29}$ This is important, because the anti-Cartesian proponent of PERCEPTUAL PARTIALITY needs to say that one's confidence that the wall is red can increase substantially at noon. For this too is essential for anti-Cartesianism's strongest motivations. For example, if having an experience offered only a slight increase in the strength of one's justification relative to what one would get from knowing about another person's experience, then the anti-Cartesian would have very limited anti-skeptical advantages over Cartesianism. For whatever the strength of our justification for perceptual beliefs might be under Cartesianism, the anti-Cartesian would be able to offer us only slightly more. That would be reassuring only if the skeptical worry was merely that we fall just slightly short of being justified in our perceptual beliefs! To to have a noteworthy anti-skeptical advantage, therefore, the anti-Cartesian must claim that the proprietary justification conferred by one's experiences is substantial. For this reason, I do not think that biting the bullet is made any more palatable by the slight increase in certainty about one's experience that might come when it actually happens.

\subsection{Second Option: Licensing Chauvinism}

A second option for the anti-Cartesian is to claim that when you know of your own future experience, that gives you stronger justification than you would get from knowing of another person's experience. If this is granted, then in ANTICIPATED EXPERIENCE you might already enjoy this stronger justification before noon, and consequently receive no additional reason to believe that the wall is red at noon. The apparent problem with this claim is that it seems to license an irrational form of chauvinism. For it seems to license one in counting one's own future experiences as stronger evidence than another person's, even in the absence of evidence that one's experiences are objectively more reliable.

It might be claimed that there is a way to avoid this kind of flagrant chauvinism. One strategy might be to claim that it can be rational to count one's own experiences as stronger evidence of the truth, even in the absence of evidence that one's experiences are objectively more reliable. For example, one might claim in the style of Crispin Wright (2004) that we have non-evidential reasons for believing that our own experiences are a reliable guide to the truth-e.g., because the pursuit of our intellectual projects requires us to accept that our own experiences are reliable, but not that other people's experiences are. ${ }^{30}$ Another strategy might be to claim that even if it would be irrational to count one's own future experiences as stronger evidence than another person's, this is not the only way that knowledge of one's future experiences to give one proprietary justification for perceptual beliefs. Perhaps if I know that I will have a reddish experience in just a moment, I don't need to infer that the wall is red from this evidence. Maybe it could somehow just make my future proprietary justification available to me now, as if I were already having the experience. ${ }^{31}$

\footnotetext{
${ }^{29}$ Although I take this point to be intuitively plausible, it can be reinforced by the familiar theorem of the probability calculus that $\operatorname{Pr}(\mathrm{p})=\operatorname{Pr}(\mathrm{p} \mid \mathrm{e}) \operatorname{Pr}(\mathrm{e})+\operatorname{Pr}(\mathrm{p} \mid \sim \mathrm{e}) \operatorname{Pr}(\sim \mathrm{e})$. Since $\operatorname{Pr}(\mathrm{p} \mid \sim \mathrm{e}) \operatorname{Pr}(\sim \mathrm{e}) \geq 0$, this theorem entails that $\operatorname{Pr}(\mathrm{p}) \geq \operatorname{Pr}(\mathrm{p} \mid \mathrm{e}) \operatorname{Pr}(\mathrm{e})$. So when for some $\delta, \operatorname{Pr}(\mathrm{e})=1-\delta$, it follows that $\operatorname{Pr}(\mathrm{p}) \geq \operatorname{Pr}(\mathrm{p} \mid \mathrm{e})(1-\delta)$, and thus that $\operatorname{Pr}(\mathrm{p}) \geq \operatorname{Pr}(\mathrm{p} \mid \mathrm{e})-\operatorname{Pr}(\mathrm{p} \mid \mathrm{e}) \delta$. And since $\delta \geq 0$ and $\operatorname{Pr}(\mathrm{p} \mid \mathrm{e}) \leq 1$, this means that $\operatorname{Pr}(\mathrm{p}) \geq \operatorname{Pr}(\mathrm{p} \mid \mathrm{e})-\delta$. Roughly put, the upshot is that $\operatorname{Pr}(\mathrm{p})$ can be less than $\operatorname{Pr}(\mathrm{p} \mid \mathrm{e})$ only to whatever extent $\operatorname{Pr}(\mathrm{e})$ is less than 1 .

${ }^{30}$ Note, however, that the Cartesian might avail himself of this, too, in an attempt to accept PERCEPTUAL PARTIALITY.

31 This strategy is inspired by (Pryor, 2013).
} 
But even if these or other responses give us plausible theoretical rationales for why knowledge of one's own future experiences can give one proprietary justification right now, they are forced to embrace counterintuitive consequences. Consider:

(Two Perceivers Sequel) All is as before in the Two Perceivers case. Then, before any blindfolds are removed, you learn some additional information. Without being told whether you or Other will be the agent whose blindfold is removed, you are informed that whoever has their blindfold removed will have an experience as of a red wall. A few minutes pass, and you are given the further information that you will be the one whose blindfold is removed.

When you learn that the agent whose blindfold is removed will have a reddish experience, this might give you some justification to believe that the wall is red. How much justification it gives you can vary, depending on how we fill in further details of the case. For although we have said that your evidence concerning the reliability of your own experiences is on a par with your evidence concerning Other's, we have left it open precisely what this evidence includes. But it also seems that no matter how we fill in these additional details, you will not get any additional justification to believe that the wall is red once you learn that it is you whose blindfold will be removed.

The anti-Cartesian who takes the second option must say otherwise. But this too licenses an updating procedure that is intuitively hard to accept as rational, in this case on account of its apparent chauvinism. For consider your situation once you know that someone will have a reddish experience, but before you learn that it will be you. If at this stage you withhold belief concerning the color of the wall, it would seem irrational for you then to grant belief once you learn that it will be you who has the reddish experience. More generally, it seems irrationally chauvinistic for you to increase your confidence that the wall is red when you learn it is you who has the reddish experience. For your evidence concerning Other's perceptual reliability and your own are equivalent.

Thus, even if the anti-Cartesian can in this way avoid saying that your justification increases at noon in ANTICIPATED EXPERIENCE, she has a different bullet to bite: licensing chauvinism. To be sure, just as with saying that your justification increases at noon, the problem with licensing chauvinism is not that the anti-Cartesian lacks a theory that can explain why this sort of chauvinism is rational. The problem is that it seems false that this sort of chauvinism is rational. Yet any view that takes knowledge of one's own future experiences to provide proprietary justification is bound to say otherwise.

\subsection{Third Option: Rejecting Evidentialism about Defeaters}

Recall that PERCEPTUAL PARTIALITY says that having an experience sometimes gives you a distinctive proprietary justification for a perceptual belief. It need not say that it does so all the time. The final response for the anti-Cartesian is to claim that your reddish experience in ANTICIPATED EXPERIENCE does not confer proprietary justification, even though in other cases your experiences can do so. An anti-Cartesian who takes this option owes us a story about what feature of the ANTICIPATED EXPERIENCE case prevents you from receiving proprietary justification from your experience. This seems tough to do. For the feature would need to be an essential feature of the case, or else the case could simply be modified to remove it. And it would need to be a feature that is plausibly absent in many ordinary cases of perception, or else anti-Cartesianism will lose its anti-skeptical force. It seems that 
the only feature fitting the bill is that in ANTICIPATED EXPERIENCE you have reflective awareness of your experience. For it is essential to the example that you know that you have a reddish experience at noon. And it is not clear that we ordinarily do know what our experiences are, even though we are able to come to know what they are if we stop to reflect. So the final option for the anti-Cartesian is to claim that this reflective awareness alone is enough to defeat the distinctive proprietary justification that those experiences otherwise would give you for perceptual beliefs.

To be clear, the idea is not that reflective awareness defeats any justification you might have for believing that the wall is red. Given the right background evidence, you can infer from the fact that Other seems to see a red wall that the wall is red, and you presumably can be in an equally good position to make such an inference from knowledge of your own experiences. Rather, the idea is that reflective awareness undermines the distinctive sort of proprietary justification that your experiences usually can provide.

Although I am more sympathetic than most are to this third option for anti-Cartesianism, it faces objections. After considering one objection that does not impress me much, I will consider another objection that is in my view stronger.

The objection that does not impress me appeals to an assumption that nothing you can do "from the armchair" can change your epistemic position. According to this assumption, the only thing that can change your epistemic position is gathering up new evidence using sensory perception. Things you do from the armchair, like reasoning through the consequences of your existing evidence, or reflecting on your existing mental states, can only help you to achieve justified beliefs about things that you already had justification to believe. If you are able to arrive at a justified belief just by reasoning through your existing evidence, then that means that you already had (propositional) justification for that belief, even before you did the reasoning. And the same goes, according to the objection, for another thing you do from the armchair: reflecting on your existing mental states, like your existing experiences. If this is right, then merely reflecting on your current experiences cannot give you a new defeater for your perceptual beliefs, since it cannot change your epistemic position at all.

I am sympathetic to the objection's contention that reasoning through the consequences of your existing evidence cannot change your epistemic position. But I think that reflection (or introspection) often changes your epistemic position-i.e., that it is a way of gathering up new evidence that you did not already have, even though it is a kind of evidence-gathering that can be done from the armchair. An example might help to reinforce the point. Suppose I ask you "How many states have names beginning with the letter 'M'?" If you know the names of all the states, then it seems that there is an important sense in which the answer to this question is already among the things implicitly built in to your current evidence. So when you reason through this evidence to a justified belief, it is plausible that you are merely coming to believe something you already were in a position to justifiably believe. But suppose I instead ask you "How many states remind you of your grandmother?" You might be able to determine the answer without getting out of your armchair. But you would have to do so through a process of internal experimentation and observation that plausibly involves acquiring new evidence. ${ }^{32}$ This does not mean that every

32 Thanks to Jim Pryor (2013) for a helpful amendment to this example. 
case of reflection changes your epistemic position in the same way. But it does speak against a general ban on reflection ever changing your epistemic position.

Now for the objection that I think is more serious. Instead of claiming that reflection cannot give you new evidence, this objection says simply that the evidence that you do gain is not a defeater for your perceptual belief. The objection appeals to a widely accepted evidentialist model of defeaters, which holds that defeaters must take the form of evidence that directly or indirectly speaks against the truth of what you believe. More precisely, the idea is that for one's awareness that $d$ to give one a defeater for the belief that $p$, the fact that $\mathrm{d}$ must either oppose one's belief by directly supporting that $\mathrm{p}$ is false, or else undermine one's existing evidence for the belief by supporting that that evidence does not really support that $\mathrm{p}$ (or something to that general effect). ${ }^{33}$

If we accept this evidentialist model of defeaters, then we apparently cannot allow reflective awareness that you have a reddish experience to give you a defeater for your belief that the wall is red. For the fact that you have a reddish experience will not in ordinary cases amount to evidence directly supporting that the wall is not red. Nor will it in any obvious way amount to evidence that your existing evidence fails to support that the wall is red. To be sure, there are difficulties in applying the usual model of undermining defeaters, which is on its home turf concerning beliefs which are justified by indirect evidence, to putatively noninferentially justified perceptual beliefs. But roughly and approximately, it seems the proponent of the evidentialist model should require an undermining defeater for a perceptual belief to take the form of evidence that one's experiences do not provide a good guide to the external world (or something to that general effect). The fact that one has taken a hallucinogenic drug might be an example of such a defeater. But the mere fact that one has a reddish experience typically is not.

Now I have some sympathy for an anti-Cartesianism that denies this evidentialist model of defeaters. But I think that anyone who takes this option owes us a positive explanation of how reflective awareness of one's experiences can defeat one's proprietary justification even without providing one with undermining evidence. Again, I do not take this option to be a non-starter, as many apparently do. But it is a difficult task to offer a satisfying explanation of how it can be accepted. ${ }^{34}$

\subsection{Conclusion}

Any kind of anti-Cartesianism worth having will allow us to accept PERCEPTUAL PARTIALITY, for without it the core motivations for anti-Cartesianism are lost. But in accepting Perceptual Partiality, the anti-Cartesian faces serious objections stemming from one's possible knowledge of one's own future experiences. One option is to simply

\footnotetext{
${ }^{33}$ See, e.g., (Weatherson, Ms., Sec. 2.1) for a recent discussion of defeaters along these lines.

34 As Karl Schafer has emphasized to me, an anti-Cartesian who takes this third option furthermore appears committed to a major concession to the skeptic. Since one will have distinctive proprietary justification for one's perceptual beliefs only so long as one is not reflectively aware of them, one will not be justified in one's perceptual beliefs in contexts where one is reflectively aware of them. I think it is not obvious whether this concedes too much to the skeptic, and I will not attempt to settle the matter here. Instead, I will note only that this concession to skepticism is not too far off from those of prominent contextualist and subject-sensitive invariantist responses to skepticism, which concede in different ways the truth of skepticism in certain kinds of reflective contexts.
} 
bite the bullet, and claim that even when one knows of an experience in advance, one gets stronger justification for a perceptual belief once one actually has the experience. Another is to license the seemingly chauvinistic practice of increasing your confidence that the wall is red upon learning that you will have a reddish experience at noon, even when you already knew that either you or Other would have such an experience. The final option is to reject evidentialism about defeaters, and claim that merely being reflectively aware of your experiences must defeat the proprietary justification that they otherwise provide.

Does the anti-Cartesian have any other options? No. For if we reject the third option, then we will say that an unreflective agent who has a reddish experience has no more justification to believe the wall is red than does an agent who has reflective awareness of her reddish experience. And if we reject the first option, then we will say that such a reflective agent, who has a reddish experience and who knows she has had it, has no more justification than an agent who knows that she will have a reddish experience but who has not had it yet. And if we reject the second option, then we will say that such an agent, who knows that she will have a reddish experience but who has not had it yet, has no more justification than does an agent who knows that someone else has had a reddish experience. So if we reject all three options, then it follows that an unreflective agent who has had a reddish experience has no more justification to believe that the wall is red than does an agent who merely knows that someone else has had such an experience-in direct contradiction of PERCEPTUAL PARTIALITY. Since the most appealing and well-motivated forms of anti-Cartesianism accept PERCEPTUAL PARTIALITY, it seems that the rejection of a Cartesian epistemology of perception brings with it some difficult choices. ${ }^{35}$

\footnotetext{
35 For helpful comments and discussion, I am grateful to Paul Boghossian, Earl Conee, Sinan Dogramaci, Hilary Kornblith, Ram Neta, Jim Pryor, Karl Schafer, Miriam Schoenfield, David Sosa, Katia Vavova, Alex Worsnip, and audiences at the University of Massachusetts Amherst, the University of Toronto, the University of Texas at Austin, Mount Holyoke College, and the Creighton Club meeting at Syracuse University.
} 


\section{References}

Barnett, David James (2014) 'What's the Matter With Epistemic Circularity?' Philosophical Studies 171(2): 177-205.

Barnett, David James (2015) 'Is Memory Merely Testimony from One's Former Self?' Philosophical Review 124(3).

Barnett, David James (MS) 'Epistemic Autonomy and the Cartesian Circle'

Briscoe, Robert (MS) 'Depiction, Pictorial Experience, and Vision Science'.

Brogaard, Berit (2013) 'Phenomenal Seemings and Sensible Dogmatism' in Seemings and Justification: New Essays on Dogmatism and Phenomenal Conservatism, Chris Tucker ed., Oxford.

Broome, John (1999) “Normative Requirements.” Ratio 12: 398-419.

Broome, John (2013) Rationality Through Reasoning, Wiley-Blackwell.

Brown, Jessica (2013) 'Immediate Justification, Perception, and Intuition' in Seemings and Justification: New Essays on Dogmatism and Phenomenal Conservatism, Chris Tucker ed., Oxford.

Chisholm, Roderick (1966) Theory of Knowledge, Englewood Cliffs, NJ: Prentice-Hall.

Christensen, David (2010) 'Higher-Order Evidence' Philosophy and Phenomenological Research 81(1): 185-215.

Cohen, Stewart (2010) 'Bootstrapping, Defeasible Reasoning, and A Priori Justification' Philosophical Perspectives 24: 141-159.

Cullison, Andrew (2010) 'What Are Seemings?' Ratio 23(3): 260-274.

Elga, Adam (2007) 'Reflection and Disagreement' Noûs 41(3): 478-502.

Foley, Richard (2001) Intellectual Trust in Oneself and Others, Cambridge University Press.

Foley, Richard (2005) 'Universal Intellectual Trust' Episteme 2(1): 5-12.

Huemer, Michael (2006) 'Phenomenal Conservativism and the Internalist Intuition' American Philosophical Quarterly 43: 147-158.

Huemer, Michael (2007) 'Compassionate Phenomenal Conservativism' Philosophy and Phenomenological Research 73: 30-55.

Jehle, David and Weatherson, Brian (2012) 'Dogmatism, Probability, and Logical Uncertainty' in New Waves in Philosophical Logic, Greg Restall and Gillian Russell eds., Palgrave Macmillan.

Kelly, Thomas (2010) 'Peer Disagreement and Higher-Order Evidence' in Social Epistemology: Essential Readings, Alvin I. Goldman and Dennis Whitcomb eds., Oxford University Press.

Kolodny, Niko (2005) 'Why be Rational?’ Mind 114: 509-563. 
Kung, Peter (2010) 'On Having No Reason: Dogmatism and Bayesian Confirmation' Synthese 177: 1-17.

Lasonen-Aarnio, Maria (2008) 'Single-Premise Deduction and Risk' Philosophical Studies 141(2): 157-173.

Lasonen-Aarnio, Maria (2014) 'Higher-Order Evidence and the Limits of Defeat' Philosophy and Phenomenological Research 88(2): 314-345.

Lasonen-Aarnio, Maria (2015) “I'm onto Something!" Learning about the World by Learning What I Think about It" Analytic Philosophy 56(4): 267-297.

Littlejohn, Clayton (2012) Justification and the Truth Connection, Cambridge University Press.

Lord, Errol (2014) 'The Real Symmetry Problem(s) for Wide-Scope Accounts of Rationality' Philosophical Studies 160(3): 443-464.

Lycan, William (2013) 'Phenomenal Conservativism and the Principle of Credulity' in Seemings and Justification: New Essays on Dogmatism and Phenomenal Conservatism, Chris Tucker ed., Oxford: Oxford University Press.

McDowell, John. (1982) 'Criteria, Defeasibility, and Knowledge' Proceedings of the British Academy 68: 455-479.

McDowell, John. (1995) 'Knowledge and the Internal' Philosophy and Phenomenological Research 55: 877-893.

Miracchi, Lisa (forthcoming) 'Competent Perspectives and the New Evil Demon Problem' in The New Evil Demon: New Essays on Knowledge, Justification, and Rationality, Fabian Dorsch and Julien Dutant eds., Oxford: Oxford University Press.

Moretti, Luca (2015) 'In Defence of Dogmatism’ Philosophical Studies 172: 261-282.

Pollock, John and Cruz, Joseph (1999) Contemporary Theories of Knowledge, 2nd ed., Rowman and Littlefield.

Pritchard, Duncan (2012) Epistemological Disjunctivism, Oxford: Oxford University Press.

Pryor, James (2000) 'The Skeptic and the Dogmatist' Noûs 34: 517-519.

Pryor, James (2005) 'There is Immediate Justification' in Contemporary Debates in Epistemology, Matthias Steup and Ernest Sosa, Oxford: Blackwell.

Pryor, James (2013) 'Problems for Credulism' in Seemings and Justification: New Essays on Dogmatism and Phenomenal Conservativism, Chris Tucker ed., Oxford University Press.

Pryor, James (MS) 'Uncertainty and Undermining'

Robson, Jon (2012) 'Aesthetic Testimony’ Philosophy Compass 7(1): 1-10.

Russell, Bertrand (1912) The Problems of Philosophy, New York: Henry Holt and Company.

Schechter, Joshua (2013) 'Rational Self-Doubt and the Failure of Closure' Philosophical Studies 163(2): 428-452. 
Schoenfield, Miriam (2014) 'Permission to Believe: Why Permissivism Is True and What It Tells Us About Irrelevant Influences on Belief' Noûs 48(2): 193-218.

Schoenfield, Miriam (2015) 'A Dilemma for Calibrationism' Philosophy and Phenomenological Research 91(2): 425-455.

Siegel, Susanna (2012) ‘Cognitive Penetrability and Perceptual Justification’ Nô̂s 46: 201-222.

Siegel, Susanna (2013) 'The Epistemic Impact of the Etiology of Experience' Philosophical Studies 162: 697-722.

Silins, Nicholas (2008) 'Basic Justification and the Moorean Response to the Skeptic' in Oxford Studies in Epistemology, vol. 2, Tamar Szabo Gendler and John Hawthorne eds., Oxford.

Sliwa, Paulina and Horowitz, Sophie (2015) 'Respecting All the Evidence' Philosophical Studies 172(11): 2835-2858.

Soteriou, Matthew (2014) 'The Disjunctive Theory of Perception' The Stanford Encyclopedia of Philosophy (Summer 2014 Edition), Edward N. Zalta ed., http://plato.stanford.edu/ archives/sum2014/entries/perception-disjunctive/.

Tucker, Chris (2010) 'Why Open-Minded People Should Endorse Dogmatism’ Philosophical Perspectives 24(1): 529-545.

Tucker, Chris (2013) 'Seemings and Justification: An Introduction' in Seemings and Justification: New Essays on Dogmatism and Phenomenal Conservatism, Chris Tucker ed., Oxford.

Vavova, Katia (2014) 'Moral Disagreement and Moral Skepticism' Philosophical Perspectives 28(1): 302-333.

Vogel, Jonathan (2014) 'E \& H' in Perceptual Justification and Skepticism, Dylan Dodd and Elia Zardini eds., Oxford.

Weatherson, Brian (2007) 'The Bayesian and the Dogmatist' Proceedings of the Aristotelian Society 107(1/2): 169-185.

Weatherson, Brian (MS) 'Do Judgements Screen Evidence?’

Wedgwood, Ralph (2007) The Nature of Normativity, Oxford University Press.

Wedgwood, Ralph (2013) 'A Priori Bootstrapping' in The A Priori in Philosophy, Albert Casullo and Joshua Thurow eds., Oxford.

White, Roger (2005) 'Epistemic Permissiveness’ Philosophical Perspectives 19(1): 445-459.

White, Roger (2006) ‘Problems for Dogmatism’ Philosophical Studies 131(3): 525-557.

Williamson, Timothy (2000) Knowledge and its Limits, Oxford University Press.

Wollheim, Richard (1980) Art and Its Objects, 2nd ed., Cambridge University Press.

Worsnip, Alex (2015) 'Narrow-Scoping for Wide-Scopers’ Synthese 192(8): 2617-2646. 
Wright, Crispin (2004) 'Warrant for Nothing (And Foundations for Free)?' Supplement to the Proceedings of the Aristotelian Society 78(1): 167-212.

Zagzebski, Linda (2012) Epistemic Authority: A Theory of Trust, Authority, and Autonomy in Belief, Oxford University Press. 